\title{
Herpes Simplex Virus (HSV)-Mediated ICAM-1 Gene Transfer Abrogates Tumorigenicity and Induces Anti-Tumor Immunity
}

\author{
Michael D'Angelica, ${ }^{1}$ Cindy Tung, ${ }^{1}$ Peter Allen, ${ }^{1}$ \\ Marc Halterman, ' Keith Delman,' Thomas Delohery,' \\ David Klimstra, ${ }^{2}$ Michael Brownlee, ${ }^{3}$ Howard Federoff, \\ Yuman Fong ${ }^{1}$ \\ Departments of ${ }^{1}$ Surgery and ${ }^{2}$ Pathology, Memorial Sloan-Kettering \\ Cancer Center, New York, New York, U.S.A. \\ ${ }^{3}$ Department of Medicine, Albert Einstein College of Medicine, Bronx, \\ New York, U.S.A. \\ ${ }^{4}$ Department of Neurology, Medicine, Microbiology and Immunology, \\ University of Rochester, Rochester, New York, U.S.A.
}

Accepted August 20, 1999.

\begin{abstract}
Background: Costimulatory and cellular adhesion molecules are thought to be essential components of antigen presentation in the immune response to cancer. The current studies examine gene transfer utilizing herpes viral amplicon vectors (HSV) to direct surface expression of adhesion molecules, and specifically evaluate the potential of a tumor-expressing intercellular adhesion molecule-1 (ICAM-1) to elicit an anti-tumor response.

Materials and Methods: The human ICAM-1 (hICAM1) gene was inserted into an HSV amplicon vector and tested in a transplantable rat hepatocellular carcinoma and in a human colorectal cancer cell line. Cell surface ICAM-1 expression was assessed by flow cytometry. Lymphocyte binding to HSV-hICAMl-transduced cells was compared with that to cells transduced with HSV not carrying the ICAM gene. Tumorigenicity of HSV-hICAMl-transduced tumor cells were tested in syngeneic Buffalo rats. Additionally, immunization with irradiated (10,000 rads) HSV-hICAMl-transduced tu-
\end{abstract}

mor cells was performed to determine its effect on tumor growth.

Results: A 20-min exposure of tumor cells at a multiplicity of infection (MOI) of 1 resulted in high-level cell surface expression of human ICAM in approximately $25 \%$ of tumor cells. Transduced rat or human tumor cells exhibited significantly enhanced binding of lymphocytes $(p<0.05)$. HSV-hICAMl-transduced cells elicited an increase in infiltration by $\mathrm{CD}^{+}$lymphocytes in vivo and exhibited decreased tumorigenicity. Immunization with irradiated HSV-hICAM1-transduced cells protected against growth of subsequent injected parental tumor cells.

Conclusions: HSV amplicon-mediated gene transfer is an efficient method for modifying the cell surface expression of adhesion molecules. Increased tumor expression of ICAM-1 represents a promising immune anti-cancer strategy.

\section{Introduction}

Cell-cell adhesion is central to an effective immune interaction between $\mathrm{T}$ cells and targets (1).

Address correspondence and reprint requests to: Dr. Yuman Fong, Department of Surgery, Memorial Sloan-Kettering Cancer Center, 1275 York Avenue, New York, NY 10021, U.S.A. Phone: 212-639-2016; Fax: 212-639-4031; E-mail: fongy@mskcc.org
Intercellular adhesion molecule-1 (ICAM-1) is a well-described adhesion molecule that mediates cell adhesion through a receptor on leukocytes known as leukocyte function antigen-1 (LFA-1) $(2,3)$. Baseline in vivo expression of ICAM-1 is usually low and limited to endothelial cells, lymphoid cells and fibroblasts. ICAM-1 expression is up-regulated in inflammatory states in vivo and by 
interleukin-1 (IL-1), tumor necrosis factor $\alpha$ (TNF$\alpha)$, and interferon $\gamma($ IFN- $\gamma)$ in vitro $(4,5)$. There is mounting evidence that ICAM-1/LFA-1-mediated cell adhesion plays a critical role in the binding of $T$ lymphocytes and may participate in immune activation. A series of studies have shown that monoclonal antibodies directed at ICAM-1 can inhibit cytotoxic T lymphocyte (CTL), natural killer (NK), and lymphokine activated killer (LAK) cell-mediated lysis of targets in vitro (6-9). Furthermore, transfection of the ICAM-1 gene into major histocompatibility complex (MHC)-deficient fibroblasts enhances stimulation of T cells (10). It has recently been postulated that the loss of ICAM-1 expression on the surface of tumor cells may be responsible for certain tumors' ability to evade the host immune system (11-13). Enhancement of expression of cell adhesion molecules such as ICAM-1, therefore, represents a potential strategy for therapeutic manipulation of anti-tumor immunity $(14,15)$.

Viral vectors are among the most efficient means of transferring foreign genes into a cell. Herpes simplex viral (HSV) amplicon vectors are particularly suited for clinical gene therapy for a variety of reasons. HSV vectors rapidly and efficiently transduce both dividing and nondividing cells, allowing gene transfer into many cell types in as little as $20 \mathrm{~min}$. Additionally, gene transfer with HSV vectors is episomal and gene expression is thus transient, which is desirable for cancer-related immunotherapy (16-20). Our previous studies have demonstrated the effectiveness of HSV vectors in transferring cytokine genes into tumor cells and eliciting significant antitumor activity by expression of these secreted proteins $(16,17,21)$. The current studies examine the potential for HSV-mediated gene transfer in eliciting tumor cell surface production of the human ICAM-1 and the resultant immune consequences.

\section{Materials and Methods}

\section{Tumor Cell Line}

The tumor cell line Morris hepatoma McARH7777 (ATCC CRL 1601) was maintained in culture [Dulbecco's modified Eagle medium (DMEM), 6.25\% fetal calf serum (FCS), 20\% horse serum, $2 \mathrm{mM}$ L-glutamine) and periodically implanted into Buffalo rat flanks to ensure tumorigenicity. The human colorectal tumor cell line HCT-8 (ATCC CCL 244) was maintained in culture (RPMI, 10\% FCS) and passaged rou- tinely. These cell lines were tested to be free of mycoplasma and viral infection.

\section{HSV Vectors}

Human ICAM-1 CDNA (purchased from R\&D Systems, Minneapolis, $\mathrm{MN}$ ) and $E$. coli $\beta$-galactosidase cDNA was directionally cloned into HSVPrPuc (HSV-hICAMl and HSVlac, respectively), which contains the HSV immediate early 4/5 promoter, a multiple cloning site, and an SV40 A sequence, and packaged as previously described $(18,19,21,22)$. Packaging of amplicon vectors was performed in RR1 cells using helper mutant D30EBA virus as previously described (21). Amplicon titers were determined by X-gal histochemical staining and by quantitative polymerase chain reaction (PCR) as described previously (21). Amplicon titer in the different virus preparations ranged from 1 to $10 \times$ $10^{7} \mathrm{pfu} / \mathrm{ml}$ and the helper titers were in the range of 5 to $15 \times 10^{7} \mathrm{pfu} / \mathrm{ml}$. HSVlac titers were between 1 and $2 \times 10^{6}$ blue-forming units $/ \mathrm{ml}$ as titered by expression and X-gal biochemistry on NIH3T3 cells. The HSV-hICAMl titers were between $\mathrm{l}$ and $2 \times 10^{6}$ particles $/ \mathrm{ml}$.

\section{In Vitro Production of ICAM-1}

Hepatoma cells from culture were radiated with 10,000 rads and rested for $1 \mathrm{hr}$. Cells were then exposed to HSV-hICAMl, HSVlac, or nothing at an MOI of 1 for $20 \mathrm{~min}$ at $37^{\circ} \mathrm{C}$. Cells were then washed with media twice and maintained in culture until analysis. To assess the cell surface expression of hICAMl, cells were harvested at 1,2 , 5 , and 7 days after transduction and washed twice with Hank's buffered salt solution (HBSS) containing $10 \mathrm{mM}$ HEPES. Separate aliquots of cells were then incubated on ice for 20 min with anti-human ICAM-1 (Clone MEMI11, Caltag, Burlingame, CA) and anti-rat ICAM-1 (Clone 1A29, Caltag) antibodies conjugated to phycoerythrin (PE) or FITC. Additional aliquots of cells were incubated with isotype controls (Caltag) to account for nonspecific binding of antibodies. Cells were then analyzed with a FACscanner (Becton Dickinson, Franklin Lakes, NJ) for the presence of human and rat ICAM.

To analyze the secretion of soluble human ICAM (sICAM), radiated cells were transduced with HSV-hICAM1, HSVlac, or nothing and plated in 12-well plates. Culture supernatants were harvested at $1,2,5$, and 7 days after transduction. Cells in representative wells were counted to standardize production to the num- 
ber of cells per well. Supernatants were aliquoted and stored at $-80^{\circ} \mathrm{C}$ until analysis. sICAM in the supernatants was quantitated by ELISA (HyCult Technologies, Uden, The Netherlands). The limit of detection for this assay was $100 \mathrm{pg} / \mathrm{ml}$.

\section{Adhesion Assay}

RAT SPLENOCYTE ADHERENCE TO RAT HEPATOMA CELLS. To determine whether ICAM-1-transduced rat hepatoma cells bound lymphocytes more avidly, a modification of previously reported adhesion assays (23) was performed. Briefly, hepatoma cells were radiated with 10,000 rads, exposed to HSV-hICAMl, HSVlac, or nothing for $20 \mathrm{~min}$ at $37^{\circ} \mathrm{C}$ and washed with media twice. Cells were then plated in nearly confluent monolayers in 96-well plates. Splenocytes were harvested from normal Buffalo rats 1 day prior to each assay and cultured overnight in complete RPMI (.01 mM NEAA, 1 mM NaPyruvate, $2 \mathrm{mM}$ L-glutamine, $50 \mu \mathrm{M} 2-\mathrm{ME}$, penicillin/steptomycin) containing $10 \%$ FCS, $50 \mathrm{U} / \mathrm{ml}$ IL-2 (Chiron, Emeryville, CA), $5 \mu \mathrm{g} / \mathrm{ml}$ Con A (Sigma, St. Louis, MO), and $50 \mathrm{ng} / \mathrm{ml}$ PMA (phorbol 12-myristate 13-acetate) (Sigma). On the day of the assay, nonadherent splenocytes were harvested at a concentration of $10^{6} / \mathrm{cc}$, and labeled with MTT [5 mg/ml phosphate-buffered saline (PBS)] in a v:v ratio of 3:1 (splenocytes: MTT). Splenocytes were incubated with MTT for $6 \mathrm{hr}$ at $37^{\circ} \mathrm{C}$ with gentle agitation every $30 \mathrm{~min}$. Before the labeled splenocytes were added, one set of wells with hepatoma cells was incubated for $2 \mathrm{hr}$ with anti-ICAMl antibody (clone HA58, PharMingen, San Diego, CA). All wells were then washed once in media, and MTT-labeled splenocytes were then added at a concentration of $1 \times 10^{6} / 100 \mu \mathrm{l}$ into each well. The cells were then coincubated for $30 \mathrm{~min}$ at $37^{\circ} \mathrm{C}$. Nonadherent lymphocytes were gently washed off with PBS. Adherent lymphocytes were lysed with dimethylsulfoxide (DMSO) and read by spectrophotometry at $570 \mathrm{~nm}$. Representative wells were used to count the number of hepatoma cells present for each experimental group. Additional labeled splenocytes were plated at varying concentrations, lysed, and read by spectrophotometry to create a standard curve for the number of splenocytes per well. An adhesion index calculated as the number of adherent lymphocytes per hepatoma target cell and the mean of 8 wells was recorded.
HUMAN LYMPHOCYTE ADHESION TO HUMAN COLORECTAL CANCER CELLS. Protocols were performed in compliance with Memorial Sloan-Kettering Cancer Center's Institutional Review Board guidelines. To determine if human colorectal cancer cells infected with HSV-hICAMI increased lymphocyte adhesion, a modified adhesion assay was performed as above. Briefly, HCT-8 cells were irradiated with 9000 rads and then infected in suspension, with either HSV-hICAMl or nothing $\left(20 \mathrm{~min}, 37^{\circ} \mathrm{C}\right)$, and then washed twice with media. Cells were then plated at a concentration of $1 \times 10^{5}$ cells/well in 96-well plates.

Human lymphocytes were then harvested as previously described (24). Briefly, $15 \mathrm{cc}$ of fresh heparinized blood was harvested from healthy human volunteers. The blood was mixed with an equal amount of PBS, and 9 cc of Ficoll-Paque (endotoxin tested, sterile; Amersham Pharmacia Biotech, Piscataway, NJ) was then layered beneath the mixture, and the gradient centrifuged at $2000 \mathrm{rpm}, 20^{\circ} \mathrm{C}$, for $30 \mathrm{~min}$ with no brake (Eppendorf, model 5810R). The monocellular layer was then harvested and washed twice in HBSS in a $v: v$ ratio of $3: 1$. The cells were incubated overnight in complete RPMI $(.01 \mathrm{mM}$ NEAA, $1 \mathrm{mM}$ NaPyruvate, $2 \mathrm{mM}$ L-glutamine, 50 $\mu \mathrm{M}$ 2-ME, penicillin/streptomycin) containing $10 \%$ FCS, $50 \mathrm{U} / \mathrm{ml} \mathrm{IL-2} \mathrm{(R \& D} \mathrm{Systems),} 5 \mu \mathrm{g} / \mathrm{ml}$ Con A (Sigma), and $50 \mathrm{ng} / \mathrm{ml}$ PMA.

Before MTT-labeled lymphocytes were added, one set of wells with HCT8 colorectal cancer cells was incubated for $2 \mathrm{hr}$ with anti-ICAMl antibody (clone HA58, PharMingen). The MTT-labeled lymphocytes and colorectal cancer cells were then coincubated $\left(30 \mathrm{~min}, 37^{\circ} \mathrm{C}\right)$, washed, lysed, and read by spectrophotometry as stated above. The mean of 5 wells was recorded over 8 days at four different time points: days $1,2,5$, and 8 .

\section{In Vitro Cell Proliferation}

To determine whether transduction of hepatoma cells with the ICAM-1 gene altered in vitro growth properties, cell proliferation assays were performed. Replicating rat hepatoma cells were exposed to HSV-hICAMl, HSVlac, or nothing at an MOI of 1 for $20 \mathrm{~min}$ at $37^{\circ} \mathrm{C}$. Cells were then plated in 24-well plates at a concentration of $10^{4}$ viable cells $/ \mathrm{ml} /$ well. Cells were harvested by trypsin disaggregation at 1,2 , and 4 days after plating and counted by trypan blue exclusion. The mean count of 8 wells per time point was compared. 


\section{Animals and Operative Procedures}

Male Buffalo rats (Harlan Sprague Dawley) were housed 2 per cage in a temperature $-\left(22^{\circ} \mathrm{C}\right)$ and humidity-controlled environment and were given water and standard rat chow (PMI Mills, St. Louis, MO) ad libitum. They were maintained in 12-hr light/dark cycles. All surgical procedures were carried out through a midline laparotomy under intraperitoneal (ip) pentobarbital $(50 \mathrm{mg} /$ $\mathrm{kg}$ ) anesthesia. For major abdominal operations, $3 \mathrm{ml}$ of $0.9 \%$ saline was administered ip for resuscitation postoperatively. All animals received care under approved protocols in compliance with Memorial Sloan-Kettering Cancer Center's Institutional Animal Care and Use Committee guidelines.

\section{Tumorigenicity Experiments}

To analyze the effects of ICAM-1 overexpression on the in vivo growth characteristics of hepatoma cells, flank tumorigenicity experiments were performed. Animals ( $n=5$ per group) were randomized to receive subcutaneous left flank injections of $10^{6}$ viable rat hepatoma cells transduced with HSV-hICAMl, HSVlac, or nothing (MOI of 1). On the opposite right flank, all animals received subcutaneous flank injections of $10^{6}$ viable nontransduced cells. Animals were weighed and tumors measured with external calipers twice weekly. Tumor measurements were made in two perpendicular dimensions and averaged. Tumor volume was calculated using the equation $4 / 3 \pi r^{3}$.

\section{Immunohistochemistry}

To assess potential immunologic mechanisms of tumor regression, immunohistochemical analysis of cell infiltrates in tumors was carried out. Animals from additional tumorigenicity experiments had tumors excised at 1 and 3 weeks after injection of cells ( $n=5$ per time point) and placed immediately in $10 \%$ buffered formalin. Twenty-four hours later, tumors were embedded in paraffin through standard techniques, and 5 - $\mu \mathrm{m}$ sections were made. Hematoxylin and eosin staining was performed through standard techniques. The following antibodies were used for immunohistochemical analysis: mouse monoclonal anti-rat CD4 (IgG1, clone W3/25, Serotec, Oxford, U.K.), mouse monoclonal antirat CD8 (IgG1, clone OX-8, Caltag), and mouse monoclonal anti-rat 1-A (IgGl, clone OX-6, Serotec), which recognizes rat MHC class II. The secondary antibody used was biotinylated antimouse IgG, rat adsorbed (Vector, Burlingame, CA). Slides used for CD4 and CD8 staining were pretreated with $1 \mathrm{mM}$ EDTA ( $\mathrm{pH} 8$ ) in a microwave for $10 \mathrm{~min}$. For MHC II staining, slides were pretreated for $10 \mathrm{~min}$ with a $0.05 \%$ protease XXIV (Sigma) in Tris-HCl buffer, pH 7.6. Endogenous peroxide was then quenched with a 5-min incubation in $3 \% \mathrm{H}_{2} \mathrm{O}_{2}$. After washes with PBS, slides were placed in $0.05 \%$ bovine serum albumin (BSA) for $1 \mathrm{~min}$. Slides were then dried and whole horse serum applied at a 1:20 dilution in $2 \%$ BSA and incubated for $10 \mathrm{~min}$. Serum was suctioned off and $150 \mu \mathrm{l}$ of primary antibody applied. The primary antibody was incubated for $16-18 \mathrm{hr}$ at $4^{\circ} \mathrm{C}$ in a humidified chamber. After PBS washes, secondary antibody was applied to the slides at a 1:500 dilution in 1\% BSA and incubated for $60 \mathrm{~min}$ at room temperature in a humidified chamber. Slides were then washed in PBS and peroxidase-conjugated streptavidin was applied at a dilution of 1:500 in 1\% BSA. Slides were then washed with PBS and transferred to a bath of $0.06 \%$ diaminobenzidine (Sigma) for 5 to $15 \mathrm{~min}$. Slides were washed in water and decolorized with $1 \%$ acid alcohol in water. Dehydration with ethanol and xylene were carried out with standard techniques and slides were mounted with Permount (Fisher, Pittsburgh, PA) mounting media.

A single pathologist blinded to the experiment reviewed the slides and graded them in the following way. Tumor cells were assessed for the presence or absence of MHC II staining. The degree of tumor infiltration with MHC II staining non-tumor cells was graded from 1 to 4 . The degree of infiltration of tumors with the total amount of $\mathrm{CD}^{+}$and $\mathrm{CD}^{+}$lymphocytes was graded from 1 to 4 . The relative percentage of $\mathrm{CD}^{+}$and $\mathrm{CD}^{+}$cells was then assessed and expressed as a ratio. Rat splenic tissue was used as a positive control for each experiment.

\section{Vaccination Experiments}

To determine whether previous exposure to ICAM-1-transduced hepatoma cells would protect against future challenges with the parental tumor, vaccination experiments were performed. Whole tumor cell vaccines were prepared as follows. Rat hepatoma cells were radiated with 10,000 rads, exposed to HSVhICAM1, HSVlac, or nothing at an MOI of 1 for $20 \mathrm{~min}$ at $37^{\circ} \mathrm{C}$ and washed twice with media. Animals ( $n=19$ per group) were then ran- 
domized to receive either transduced cell type by intrasplenic injections of $10^{6}$ cells in $200 \mu \mathrm{l}$ of media on day 1 . Control animals received $200 \mu \mathrm{l}$ of media intrasplenically. Three weeks after vaccination, animals were challenged with $5 \times 10^{5}$ replicating hepatoma cells by intrasplenic injection. After $10 \mathrm{~min}$, a splenectomy was performed in all animals. Three weeks after challenge, animals were sacrificed and liver surface tumor nodules counted. Body weights were recorded and grooming habits monitored twice a week throughout the experiment.

\section{Statistics}

Values are expressed as mean \pm SEM. Values were compared by two-tailed Students $t$-test or ANOVA for multiple comparisons (SPSS software package, v. 7, Chicago, IL). $p$ values of 0.05 or less were considered significant.

\section{Results}

\section{In Vitro ICAM Production}

With PE labeling, $>90 \%$ of normal untreated rat hepatoma cells expressed rat ICAM on the cell surface with mean fluorescent intensities ranging from 200 to 288 . There was no difference in rat ICAM expression between transduced and nontransduced cells. Cells transduced with HSVlac or no vector had no detectable surface human ICAM-1. Flow-cytometric analysis of rat hepatoma cells transduced with HSV-hICAMl is illustrated in Figure 1. A 20-min exposure, at an MOI $=1$, resulted in high-level expression of human ICAM on the surface of tumor cells. Peak cell surface positivity for human ICAM-1 was found $24 \mathrm{hr}$ after transduction and tapered off by 1 week (the percentage of cells positive for hICAMl was $25 \%, 16 \%$, and $9 \%$ on days 1,2 , and 5 post-transduction). Mean fluorescent intensity of human ICAM-1 on HSV-hICAMItransduced cells was 450,271 , and 124 on days

\section{Anti-human ICAM (FITC)}
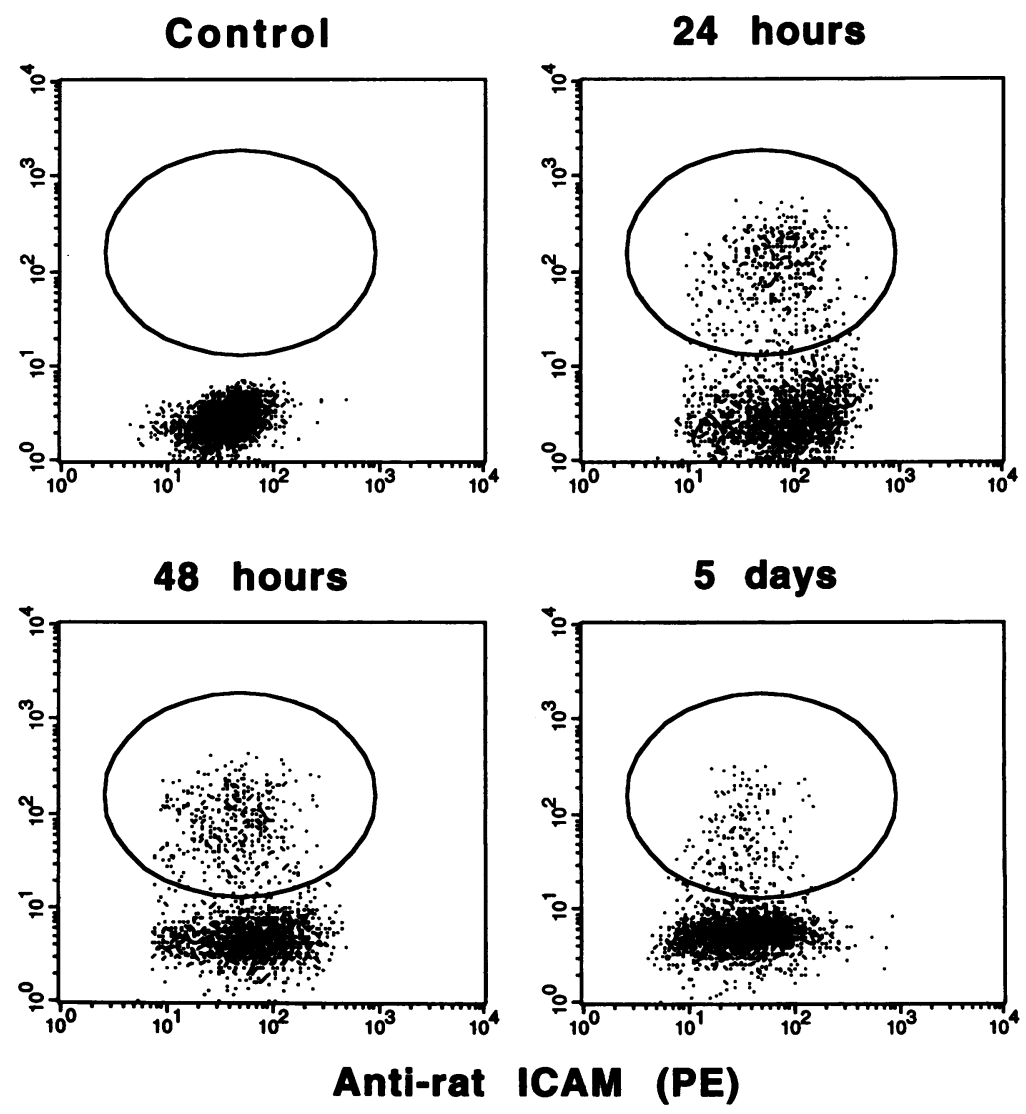

Fig. 1. Representative scattergrams of flow-cytometric results for human ICAM-1 expression in HSVhICAM 1-transduced Morris hepatoma cells at 1, 2, and 5 days after transduction. 
1,2 , and 5, respectively. On day 7 post-transduction with HSV-hICAMl, only $4 \%$ of viable cells were positive for surface hICAMl.

Figure 2 illustrates the quantitation of soluble human ICAM found in cell culture supernatants of transduced cells. No soluble human ICAM was detectable in supernatants of cells transduced with HSVlac or nothing. Levels in supernatants of transduced cells peaked at $48 \mathrm{hr}$ after transduction and approached the level of detection by day 7 .

\section{Adhesion}

To determine whether hICAMl gene transfer would alter rat lymphocyte binding by transduced tumor, an in vitro lymphocyte binding assay was used. Transduction by HSVlac or exposure of hepatoma cells to media did not alter lymphocyte binding $\left(5517 \times 10^{3}\right.$ lymphocytes/ $10^{4}$ hepatoma targets). There was a significant $(p<0.05)$ increase in the number of adherent lymphocytes per hepatoma target cell in wells containing HSV-hICAMl-transduced cells (205 \pm 15 at day one; $145 \pm 10$ at day two; $110 \pm 12$ at day five) compared to lac-transduced and untreated cells. Specific antibody to human ICAM-1 neutralized this increase in binding.

These findings were confirmed in experiments with human lymphocytes and human tumor. To determine whether hICAMl gene transfer would enhance lymphocyte binding in human cells and to characterize these effects over time, an in vitro lymphocyte binding assay was carried out over 8 days. At 24 hr there was a significant increase in the number of adherent lymphocytes per colorectal cancer cell in wells

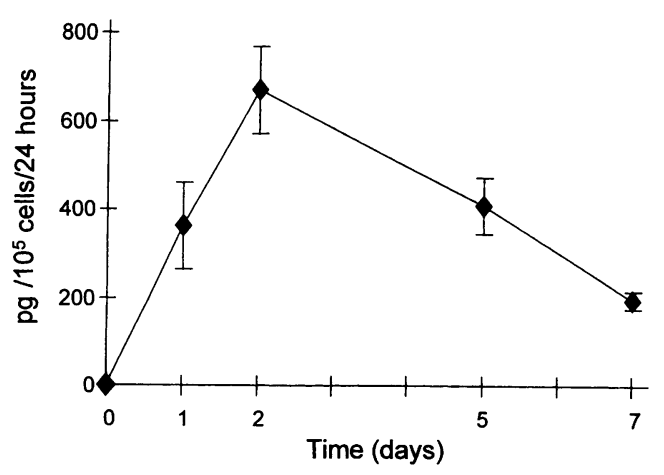

Fig. 2. Levels of soluble human ICAM by ELISA 1, 2, 5, and 7 days after transduction of radiated Morris hepatoma cells with HSVhICAM1. Values expressed as mean \pm SEM.

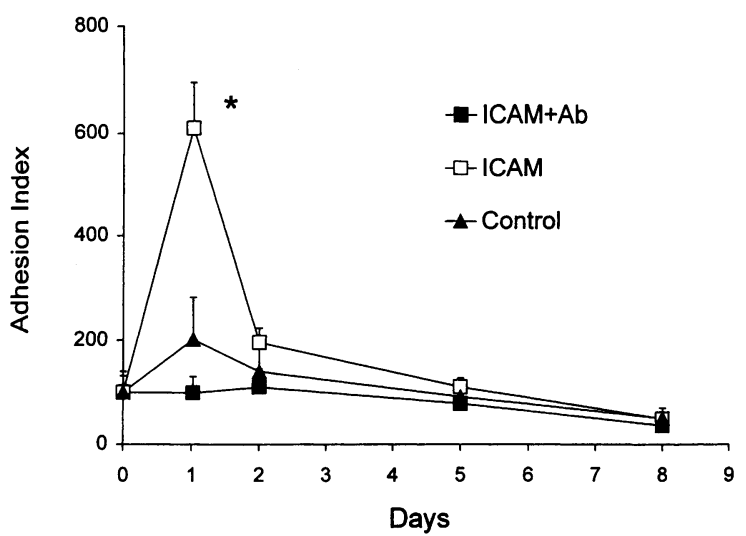

Fig. 3. Graphical representation of adhesion. Adhesion index over 8 days in human lymphocytes (no. of adherent lymphocytes $\times 10^{3}$ per $10^{5}$ human colorectal cancer target cell). Human colorectal HCT8 cells were transduced with HSV-hICAMl (open squares), nontransduced controls (filled triangles), or incubated with antibodies to hICAMl after transduction with HSV-hICAM1 prior to the adhesion assay (filled squares). ${ }^{*} p=0.007$ versus controls and antibody-blocked cells.

containing HSV-hICAMl-infected cells compared to untreated cells $(p=0.007)$. Administration of anti-ICAMl antibody eliminated this effect such that there was no difference between antibody-treated HSV-hICAM-transduced cells and nontransfected controls (Fig. 3).

\section{In Vitro Cell Proliferation}

Cells transduced with HSV-hICAMl grew similarly in culture compared to HSVlac-transduced cells and untreated cells, indicating that changes in in vivo tumor growth (below) cannot be accounted for by changes in intrinsic growth rate of the modified tumor (Fig. 4).

\section{In Vivo Tumorigenicity}

There was significantly decreased tumor growth in the left flanks of animals injected with HSVhICAMl-transduced cells compared to controls (Fig. 5). Tumor volumes at the termination of the experiment were compared. Tumors transduced with HSV-hICAMl had a significantly $(p<0.05)$ smaller volume $\left(1397 \pm 1296 \mathrm{~mm}^{3}\right)$ than that of tumors transduced with HSVlac $\left(7109 \pm 2118 \mathrm{~mm}^{3}\right)$ and untreated tumors $\left(13,556 \pm 3354 \mathrm{~mm}^{3}\right)$. The slight reduction in tumor growth in animals treated with HSVlac likely reflects the trauma of the injections combined with the cytotoxicity of helper virus in the 


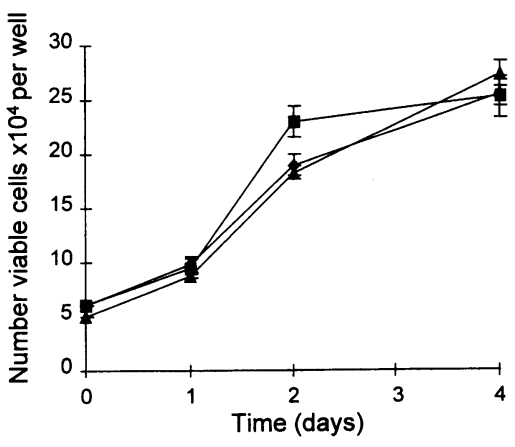

Fig. 4. In vitro proliferation of rat hepatoma cells transduced with HSV-hICAMl (triangles), HSVlac (squares), or nothing (diamonds).

Mean \pm SEM of 8 wells per group per time point is shown. Experiments were repeated twice with similar results.

HSVlac preparation. On the contralateral untreated side, all groups had progressive tumor growth that was not significantly different.

\section{Immunohistochemistry}

The ratio of $\mathrm{CD} 4$ to total $\mathrm{CD}^{+}{ }^{+}$and $\mathrm{CD} 8^{+} \mathrm{T}$ cells did not differ between groups at 1 week, but at 3 weeks, there was a significant increase in this ratio in the HSV-hICAMl-treated animals compared to HSVlac and untreated animals (0.42 vs. 0.25 and $0.24, p<0.05$ ). There was no significant difference in the degree of infiltration of tumors with MHC II staining immune cells between treatment groups at 1 and 3 weeks. Tumor cells did not stain positively for MHC II expression in any case.

\section{Intrahepatic Vaccination}

Throughout the experiment, there was no difference in weight gain among treatment groups and all animals maintained normal grooming habits. As illustrated in Figure 6, there was significantly decreased uptake and growth of hepatic metastases in animals vaccinated with HSV-hICAMl cells compared to all controls $(p \leq 0.05)$. There was no difference between animals vaccinated with HSVlac-transduced cells, radiated cells alone, or media.

\section{Discussion}

Stimulation of the host immune response against tumor antigens has shown great promise as an

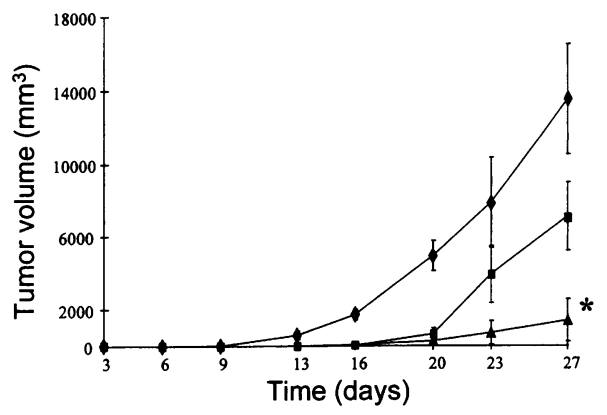

Fig. 5. Graphical representation of tumor growth in the left flank of rats. Rats $(n=5$ per group) were injected with $10^{6}$ viable hepatoma cells transduced with HSV-hICAMl (triangles), HSVlac (squares), or nothing (diamonds). Values are expressed as mean \pm SEM. *Three out of 5 animals failed to develop palpable tumors. Experiment was repeated once.

anticancer strategy. Systemic administration of cytokines such as IL-2 has shown efficacy in some patients with advanced malignancies, but use of IL-2 is limited by its significant toxicity $(25,26)$. Gene therapy strategies utilizing genes coding for immunostimulatory cytokines such as IL-2, IL-4, IL-6, IL-7, TNF, IFN- $\gamma$ and granulocyte-macrophage colony-stimuling factor (GMCSF) (27-37) have shown promise in enhancing the host anti-tumor immune response in animal models. The expression of cell surface proteins that may bind and/or stimulate $\mathrm{T}$ lymphocytes and enhance antigen presentation represents another potential immunostimulatory anti-tumor

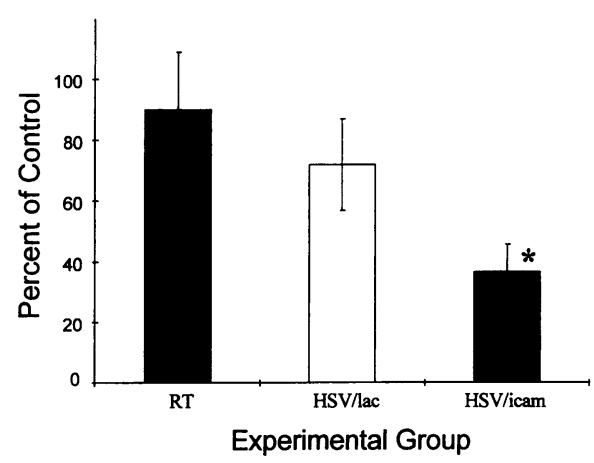

Fig. 6. Number of surface tumor nodules in rat livers. Rat livers ( $n=19$ per group) after challenge with $5 \times 10^{5}$ viable hepatoma cells. Three weeks prior to challenge, animals underwent intraportal vaccination with media (control), $10^{6}$ radiated cells alone (solid bar), $10^{6}$ radiated cells transduced with HSVlac (empty bar), or $10^{6}$ radiated cells transduced with HSV-hICAMl (gray bar). ${ }^{*} p \leq 0.05$ versus all controls. 
strategy. The costimulatory B7 molecules are cell surface proteins that have been used successfully in experimental models $(38-40)$ and are now under evaluation in human clinical trials (41). The use of tumor cells engineered to constitutively express the adhesion molecule ICAM-1 represents another novel approach for enhancing anti-tumor immunity in vivo.

The role and clinical significance of ICAM-1 in cancer are multifold. It is clear that many malignant cell types express ICAM-1 on its cell surface (42). In murine models, the level of soluble ICAM- 1 shed from melanoma was found to correlate with tumor burden (43). Expression and overexpression of ICAM-1 on the tumor cells can potentially have beneficial as well as detrimental effects. Tumor cell surface ICAM-1 expression has been postulated to have negative effects in promoting biologic activities important in the metastatic process, including tumor transport, endothelial cell adhesion, and angiogenesis $(44,45)$. However, there is a growing body of literature that indicates the alternative: that ICAM-1 overexpression may improve host tumor surveillance. ICAM-1 cell surface expression is critical for lymphocyte adhesion to antigenpresenting cells (APCs) and for T cell-mediated cytolysis $(1,3)$. Monoclonal antibody experiments have shown that the loss of ICAM-1/LFA1-mediated adhesion can prevent $\mathrm{T}$ cell adhesion and cytolysis of targets (6-9). Cellular transfection experiments have demonstrated that interaction between ICAM-1 and the LFA-1 receptor is critical for effective HLA class II-restricted and allospecific $\mathrm{T}$ cell activation (10). Thus, there is much evidence that ICAM- 1 is involved in activation of cellular immunity. The current study demonstrates that expression of cell surface ICAM-1 can be enhanced by transduction with the hICAMI gene through HSV vectors and result in increased adhesion of lymphocytes in a specific manner that can be blocked by antibodies to hICAM-1.

Attempts have therefore been made to modulate tumor surveillance in animal models by enhancement of ICAM-1 expression. Wei et al. (15) examined effects of transducing rat ICAM or human ICAM into rat tumor cells. Tumorigenicity was significantly decreased with transfection with constructs coding either rat or human ICAM-1. The authors found that vaccination with rat tumor cells expressing human ICAM-1 also attenuated growth of established tumors in a model of peritoneal metastases in Fisher rats, whereas vaccination with tumor cells expressing rat ICAM-1 had no demonstrable effect. Wei et al. concluded that these findings for tumor cells transfected with human ICAM-1 gene were due in part to the xenogeneic nature of the human ICAM-1 protein in their rat model. While this is probably one reason why the human ICAM-1 expression proved more efficacious than expression of rat ICAM-1, there are many possible explanations for vaccination with rat ICAM-1 cells having no effect on outcome in their models of established tumor. It is likely that the experimental protocol of vaccination on day 9 after peritoneal injection of parental tumor cells, a time when animals have already begun to die, is too severe a model. In addition, it is possible that lymphocyte binding without other stimulatory signals may be insufficient for effective anti-tumor effector actions. There is abundant data in other models to show that accentuated expression of syngeneic ICAM-1 will produce potent anti-tumor effects. Treatment of human melanoma and colon cancer cell lines with IFN- $\gamma$ increases expression of ICAM-1 and increases vulnerability of these cells to macrophage-mediated killing (46). Such increased susceptibility is specific and can be blocked by anti-ICAM-1 antibodies. ICAM-1 gene transfer has also been used successfully to increase host surveillance for experimental tumors. Sartor et al. (14) transfected a murine fibrosarcoma cell line with the gene encoding the murine ICAM-1 and selected out clones of ICAM-expressing cells. Tumorigenicity of expressing clones was significantly decreased, though no assessment of long-term immunity was performed. Uzendoski et al. utilized a recombinant vaccinia virus expressing murine ICAM-1 to produce induction of anti-tumor response (47). MC38 murine colon carcinoma cells infected with this vaccinia virus had decreased tumorigenicity. Vaccination with such modified tumor cells protected against subsequent tumor challenge.

Thus, there is a good biologic basis to support investigation of ICAM-1 gene transfer as immunomodulation in cancer therapy. Ultimately, however, human testing is necessary to determine utility of this approach; what is needed is a clinically useful delivery system for the human ICAM-1 gene. In this regard, our work adds significantly to these previously published studies in providing a clinically relevant system for testing the utility of ICAM-1 gene therapy in humans. In the present study, tumor cells were subjected to a single 20 -min exposure to HSV vectors and tested for biological activity without 
selection for only the human ICAM-expressing cells. Despite the fact that only a percentage of cells was transduced, we were still able to induce significant binding of lymphocytes and to elicit an immunological reaction. We are able to reproduce all of the effects of ICAM-1 gene transfer seen in previous works by Wei et al. (15) without the time-consuming process of cell selection. Whether similar biologic effects can be seen in vivo and will be clinically useful awaits trials in humans.

HSV vectors are an excellent vector for use in gene therapy directed at cancer. This report extends prior findings from our laboratories and others $(16,17,19,21,48)$ that HSV vectors are a rapid and efficient means of transferring genes of interest into dividing or nondividing cells. Transduction of tumor cells can be accomplished efficiently in $20 \mathrm{~min}$ and expression is relatively high for at least 1 week. A recent publication from our laboratories has demonstrated the feasibility of harvesting fresh tumor samples at operation, followed by radiation and successful transduction with HSV vectors to elicit high local production of secreted proteins such as IL-2 or GM-CSF (22). The current study indicates that HSV-mediated gene transfer may also lead to high-level expression of cell surface proteins. Given the rapidity and efficiency of HSV-mediated gene transfer, a clinical vaccination protocol using these vectors appears imminently feasible.

Initial human trials using systemic immunostimulatory cytokines were done on patients who had extensive tumor burdens and no other treatment options. While some responses to immunotherapy were noted, complete responses were rare $(49,50)$. Immunotherapy utilizing gene therapy for the treatment of cancer will likely be most effective in the treatment of microscopic or minimally residual tumor. Hepatic malignancy is a good model of microscopic residual disease because in most patients who undergo resection of tumor, disease recurs in the remnant liver, thus implicating residual microscopic hepatic disease at the time of operation as the cause for therapeutic failures. We investigated an intraportal vaccination strategy with hepatoma cells transduced with the human ICAM-1 gene and have demonstrated that this strategy can decrease growth of microscopic disease in the liver. In a similar rat hepatoma model, we have shown that by combining immunotherapy targeting macrophage activity with INF- $\gamma$ and lymphocyte activity with IL-2 or GM-CSF, we can stimulate more effective anti- tumor immunity than either modality alone (21). It is likely that a clinically relevant, immunostimulatory anti-cancer strategy will consist of multitargeted therapy. Some combination of tumor-expressed genes, including chemokines to attract immune cells to the tumor target, cell adhesion molecules to bind immune cells, and cytokines to activate the immune cells, holds promise. This report contributes to the evidence that the up-regulation of cell adhesion molecules using gene transfer strategies is a potentially useful method of binding immune cells at sites of tumor. These studies indicate that ICAM-1 is a therapeutic target and encourages studies combining induction of cell surface ICAM expression with other immunostimulatory strategies.

\section{Acknowledgments}

This work was supported in part by grants CA76416 and CA72632 from the National Institutes of Health and from the Sara Chait Foundation.

\section{References}

1. Dustin ML, Springer TA. (1991) Role of lymphocyte adhesion receptors in transient interactions and cell locomotion. Annu. Rev. Immunol. 9: 2766.

2. Rothlein R, Dustin ML, Marlin SD, Springer TA. (1986) A human intercellular adhesion molecule (ICAM-1) distinct from LFA-1. J. Immunol. 137: 1270-1274.

3. Springer TA. (1990) Adhesion receptors of the immune system. Nature 346: 425-434.

4. Voraberger G, Schafer R, Stratowa C. (1991) Cloning of the human gene for intercellular adhesion molecule $l$ and analysis of its 5'-regulatory region: Induction by cytokines and phorbol ester. J. Immunol. 147: 2777-2786.

5. Dustin ML, Rothlein R, Bhan AK, Dinarello CA, Springer TA. (1986) Induction by IL 1 and interferon-gamma: Tissue distribution, biochemistry, and function of a natural adherence molecule (ICAM-1). J. Immunol. 137: 245-254.

6. Katsumoto Y, Monden T, Takeda T, et al. (1996) Analysis of cytotoxic activity of the CD4 positive $T$ lymphocytes generated by local immunotherapy. Br. J. Cancer 73: 110-116.

7. Fady C, Gardner A, Gera JF, Lichtenstein A. (1993) Interferon-gamma-induced increased sensitivity of HER2/neu-overexpressing tumor cells to lymphokine-activated killer cell lysis: Importance of ICAM-1 in binding and post-binding events. Cancer Immunol. Immunother. 37: 329-336. 
8. Boyer MW, Orchard PJ, Gorden KB, Anderson PM, McIvor RS, Blazar BR. (1995) Dependency on intercellular adhesion molecule recognition and local interleukin-2 provision in generation of a in vivo CD8 positive T-cell immune response to $\mathrm{mu}$ rine myeloid leukemia. Blood 85: 2498-2506.

9. Makgoba MW, Sanders ME, Ginther Luce GE, et al. (1988) Functional evidence that intercellular adhesion molecule-1 (ICAM-1) is a ligand for LFA-1-dependent adhesion in T cell-mediated cytotoxicity. Eur. J. Immunol. 18: 637-640.

10. Altmann DM, Hogg N, Trowsdale J, Wilkinson D. (1989) Cotransfection of ICAM-1 and HLA-DR reconstitutes human antigen-presenting cell function in mouse L cells. Nature 338: 512-514.

11. Vanky F, Wang P, Patarroyo M, Klein E. (1990) Expression of the adhesion molecule ICAM-1 and major histocompatibility complex class I antigens on human tumor cells is required for their interaction with autologous lymphocytes in vitro. Cancer Immunol. Immunother. 31: 19-27.

12. Gregory CD, Murray RJ, Edwards CF, Rickinson AB. (1988) Downregulation of cell adhesion molecules LFA-3 and ICAM-1 in Epstein-Barr viruspositive Burkitt's lymphoma underlies tumor cell escape from virus-specific $\mathrm{T}$ cell surveillance. $J$. Exp. Med. 167: 1811-1824.

13. Dustin ML, Staunton DE, Springer TA. (1988) Supergene families meet in the immune system. Immunol. Today 9: 213-215.

14. Sartor WM, Kyprianou N, Fabian DF, Lefor AT. (1995) Enhanced expression of ICAM-1 in a murine fibrosarcoma reduces tumor growth rate. J. Surg. Res. 59: 66-74.

15. Wei $\mathrm{K}$, Wilson JG, Jurgensen $\mathrm{CH}$, Iannone MA, Wolberg G, Huber BE. (1996) Xenogeneic ICAM-1 gene transfer suppresses tumorigenicity and generates protective antitumor immunity. Gene Ther. 3: 531-541.

16. Herrlinger U, Kramm CM, Aboody-Guterman KS, et al. (1988) Pre-existing herpes simplex virus 1 (HSV-1) immunity decreases, but does not abolish, gene transfer to experimental brain tumors by a HSV-1 vector. Gene Ther. 5: 809-819.

17. Kramm CM, Chase M, Herrlinger U, et al. (1997) Therapeutic efficiency and safety of a second-generation replication-conditional HSVl vector for brain tumor gene therapy. Hum. Gene Ther. 8: 2057-2068.

18. Geller AI, Keyomarsi K, Bryan J, Pardee AB. (1990) An efficient deletion mutant packaging system for defective herpes simplex virus vectors: Potential applications to human gene therapy and neuronal physiology. Proc. Nat. Acad. Sci. U.S.A. 87: 8950-8954.

19. Fong YF, Federoff HJ, Brownlee M, Blumberg D, Blumgart LH, Brennan MF. (1995) Rapid and efficient gene transfer in human hepatocytes by herpes viral vectors. Hepatology 22: 723-729.

20. Geller AI, Federoff H. (1991) The use of HSV-1 vectors to introduce heterologous genes into neurons: Implications for gene therapy. In: CohenHaguenauer M, Boiron M (eds). Human Gene Transfer. John Libbey Eurotext, Paris, pp. 63-73.

21. Karpoff H, D'Angelica M, Blair S, Brownlee MD, Federoff H. (1997) Prevention of hepatic tumor metastases in rats with herpes viral vaccines and gamma-interferon. J. Clin. Invest. 99: 799-804.

22. Tung C, Federoff HJ, Brownlee M, Karpoff $\mathrm{H}$, Weigel T, Brennan MF, Fong Y. (1996) Rapid production of interleukin-2-secreting tumor cells by herpes simplex virus-mediated gene transfer: Implications for autologous vaccine production. Hum. Gene Ther. 7: 2217-2224.

23. Miki I, Ishihara N, Otoshi M, Kase H. (1993) Simple colorimetric cell-cell adhesion assay using MTT-stained leukemia cells. J. Immunol. Methods 164: 255-261.

24. Kanof ME, Smith PD, Zola H. (1996) Preparation of human mononuclear cell populations and subpopulations. In: Coligan JE, Kruisbeek AM, Margulies DH, Shevah EM, Strober W. (eds). Current Protocols in Immunology. John Wiley \& Sons, New York, p. 7.1.1-7.1.7.

25. Herberman RB. (1989) Interleukin-2 therapy of human cancer: Potential benefits versus toxicity. J. Clin. Oncol. 7: 1-4.

26. Lee RL, Lotze MT, Skibber JM, et al. (1989) Cardiorespiratory effects of immunotherapy with interleukin-2. J. Clin. Oncol. 7: 7-20.

27. Iwanuma Y, Kato K, Yagita H, Okumura K. (1995) Induction of tumor-specific cytotoxic $\mathrm{T}$ lymphocytes and natural killer cells by tumor cells transfected with the interleukin-2 gene. Cancer Immunol. Immunother. 40: 17-23.

28. Ley V, Langlade-Demoyen P, Kourilsky P, Larsson-Sciard E. (1991) Interleukin 2-dependant activation of tumor specific cytotoxic T lymphocytes in vivo. Eur. J. Immunol. 21: 851-854.

29. Dranoff G, Jaffee E, Lazenby A, et al. (1993) Vaccination with irradiated tumor cells engineered to secrete murine granulocyte-macrophage colonystimulating factor stimulates potent, specific, and long-lasting anti-tumor immunity. Proc. Natl. Acad. Sci. U.S.A. 90: 3539-3543.

30. Levitsky H, Lazenby A, Hayashi RJ, Pardoll DM. (1994) In vivo priming of two distinct antitumor effector populations: The role of MHC class I expression. J. Exp. Med. 179: 1215-1224.

31. Golumbek P, Lazenby A, Levitsky HI, et al. (1991) Treatment of established renal cancer by tumor cells engineered to secrete interleukin-4. Science 254: 713-716.

32. Porgador A, Tzehoval E, Katz A, et al. (1992) Interleukin 6 gene transfection into Lewis lung carcinoma tumor cells suppresses the malignant phenotype and confers immunotherapeutic competence against parental metastatic cells. Cancer Res. 52: 3679-3686.

33. Eisenthal A, Skornick Y, Merimsky O, et al. (1993) 
Effect of allogeneic tumor cells, interleukin-2 and interleukin-6, on the growth of subcutaneous syngeneic tumors. Cancer Immunol. Immunother. 37: 233-239.

34. Connor J, Bannerji R, Saito S, Heston W, Fair W, Gilboa E. (1993) Regression of bladder tumors in mice treated with interleukin 2 gene modified tumor cells. J. Exp. Med. 177: 1127-1134.

35. Allione A, Consalvo M, Nanni P, et al. (1994) Immunizing and curative potential of replicating and nonreplicating murine mammary adenocarcinoma cells engineered with interleukin (IL)-2, IL-4, IL-6, IL-7, IL-10, tumor necrosis factor alpha, granulocyte-macrophage colony-stimulating factor, and gamma-interferon gene or admixed with conventional adjuvants. Cancer Res. 54: 6022-6026.

36. Fearon ER, Pardoll DM, Itaya T, et al. (1990) Interleukin-2 production by tumor cells bypasses $\mathrm{T}$ helper function in the generation of an antitumor response. Cell 60: 397-403.

37. Hock H, Dorsch M, Kunzendorf U, Qin Z, Diamantstein T, Blankenstein T. (1993) Mechanisms of rejection induced by tumor cell-targeted gene transfer of interleukin 2, interleukin 4, interleukin 7, tumor necrosis factor, or interferon gamma. Proc. Natl. Acad. Sci. U.S.A. 90: 2774-2778.

38. Townsend SE, Allison JP. (1993) Tumor rejection after direct costimulation of CD8 positive cells by B7-transfected melanoma cells. Science 259: $368-$ 370.

39. Baskar B, Ostrand-Rosenberg S, Nabavi N, Nadler LM, Freeman GJ, Glimcher LH. (1993) Constitutive expression of $\mathrm{B} 7$ restores immunogenicity of tumor cells expressing truncated major histocompatibility complex class II molecules. Proc. Natl. Acad. Sci. U.S.A. 90: 5687-5690.

40. Chen L, Ashe S, Brady WA, (1992) Costimulation of antitumor immunity by the B7 conterrecptor for the $T$ lymphocyte molecules CD28 and CTLA-4. Cell 71: 1093-1102.

41. Roth JA, Cristiano RJ. (1997) Gene therapy for cancer: What have we done and where are we going? J. Natl. Cancer Inst. 89: 21-39.

42. Johnson JP. (1991) The role of ICAM-1 in tumor development [review]. Chem. Immunol. 50: 143163.

43. Becker JC, Drummer R, Hartmann AA, Burg G, Schmidt RE. (1991) Shedding of ICAM-1 from human melanoma cell lines induced by IFN- $\gamma$ and tumor necrosis factor- $\alpha$. J. Immunol. 147: 43984401.

44. Simmons DL. (1995) The role of ICAM expression in immunity and disease [review]. Cancer Surv. 24: 141-155.

45. Koyama S. (1994) Immunosuppressive effect of shedding intercellular adhesion molecule 1 antigen on cell-mediated cytotoxicity against tumor cells. Jpn. J. Cancer Res. 85: 131-134.

46. Webb DS, Mostowski HS, Gerrard TL. (1991) Cytokine-induced enhancement of ICAM-1 expression results in increased vulnerability of tumor cells to monocyte-mediated lysis. J. Immunol. 146: 3682-3686.

47. Uzendoski K, Kantor JA, Abrams SI, Schlom J, Hodge JW. (1997) Construction and characterization of a recombinant vaccinia virus expressing murine intercellular adhesion molecule-1: Induction and potnetiation of anti-tumor responses. Hum. Gene Ther. 8: 851-860.

48. Lu B, Gupta S, Federoff H. (1995) Ex vivo hepatic gene transfer in mouse using a defective herpes simplex virus-1 vector. Hepatology 21: 752-759.

49. Lotze MT, Chang AE, Seipp CA, Simpson C, Vetto JT, Rosenberg SA. (1986) High-dose recombinant interleukin 2 in the treatment of patients with disseminated cancer. JAMA 256: 3117-3124.

50. Rosenberg SA, Lotze MT, Muul LM, et al. (1987) A progress report on the treatment of 157 patients with advanced cancer using lymphokine-activated killer cells and interleukin-2 or high-dose interleukin-2 alone. N. Engl. J. Med. 316: 889897. 